\title{
Decarbonising Australian cities: A new model for creating low carbon, resilient cities
}

\author{
Rauland, V. and Newman, $P$. \\ Curtin University Sustainability Policy Institute \\ Email: v.rauland@,curtin.edu.au and p.newman@,curtin.edu.au
}

\begin{abstract}
Australia currently has one of the largest per capita carbon and ecological footprints in the world. It also has a rapidly rising population with significant growth expected into the future. This paper analyses Australia's existing infrastructure and urban form, the carbon implications associated with it, along with the resources needed to sustain this way of life. The paper demonstrates how the current design of Australian cities based on large houses in low density, dispersed suburbs, which are highly car dependent is extremely resource and emission intensive and ultimately unsustainable. It is argued that the large scale, centralised management of resources, based on outdated technologies and compounded by aging infrastructure further exacerbates the problem. If Australia continues under this 'business as usual' scenario, an increase in emissions, along with numerous resource concerns can be expected. The authors contend, therefore, that Australia urgently needs to transform its cities to embrace new low carbon designs and more efficient and resilient urban systems and processes to ensure the long-term viability of Australian cities. A new model for cities is thus proposed, which is based around the concept of decentralized management of resources using new, low carbon technologies that appear to function best at the precinct level. These can help to create more integrated and resilient infrastructure systems within our cities that will greatly improve efficiency. The technologies outlined, however, are dependent on the urban form in that they are only effective and economically viable if sufficient density exists. In the case of Australian cities, this would therefore involve increasing the density in many areas, especially new centres. Adding density has numerous other benefits such as enabling better public transport infrastructure, which will reduce car dependency and the related transported emissions. Using density to transform cities can also improve quality of life by offering more local amenities and better lifestyles.
\end{abstract}

Keywords: Decarbonising, Green Infrastructure, Decentralised Resource Management, Density 


\section{INTRODUCTION}

Australia currently has one of the highest per capita carbon and ecological footprints in the world (Garnaut 2008, Global Footprint Network 2010) as well as one of the fastest growing populations for a developed country (Productivity Commission 2010b). This raises fears around Australia's ability to cope with environmental pressures such as the impacts of peak oil, climate change and other resource scarcities.

The paper begins by examining the current city system in terms of urban form and resource management in order to illustrate some of the primary reasons behind Australia's disproportionately large carbon and ecological footprints. It is argued that the low-density design of Australian cities, serviced by antiquated, centralised infrastructure is the underlying problem that is driving emissions and exacerbating the environmental and resource problems. Opportunities and measures for reducing emissions within cities are then provided based on a new city model that promotes decentralized management of resources. This model offers numerous other benefits, particularly pertinent in the $21^{\text {st }}$ century including the ability to provide greater independence and resilience in the face of natural and human made (i.e. geopolitical) disasters. The relationship between the decarbonising measures identified and density is then explored. The paper concludes by proposing that a shift to a new type of city model based on higher density and distributed systems can help significantly in reducing the carbon and ecological footprint of Australian cities.

\section{THE UNDERLYING PROBLEM}

\subsection{Consumption}

Australian cities are characterised by large, detached, single-family houses situated in low-density, dispersed suburbs (Commonwealth of Australia 2010b, Newman and Kenworthy 1999). Vast amounts of resources, including energy, water and raw materials are required to sustain these suburban environments. Significant research has demonstrated that higher carbon emissions are associated with low density, sprawled settlements compared to higher density, more compact urban form (Kahn \& Glaeser 2010, Dodman 2009, Fuller and Crawford 2011, Newton 1997, Newman \& Kenworthy 1999).

Kahn and Glaeser (2010) found that suburban houses consume up to $88 \%$ more electricity than inner city apartments. This is due to suburban houses being traditionally larger than their urban counterparts, requiring significantly more energy for heating, cooling and running additional appliances (Kahn \& Glaeser 2010). Detached houses are also less thermally efficient compared to compact, denser dwellings, which benefit from being structurally closer together (Pitt 2010). Despite improvements in energy efficiency of buildings over the years, per capita energy consumption continues to rise in line with increasing house size and compounded by decreasing occupancy (Fuller \& Crawford 2011, Commonwealth of Australia 2008).

The embodied energy, or the emissions associated with the materials used to construct houses is also considerably greater for larger dwellings. This is often excluded from discussions on the emissions contribution of buildings or the built environment although a growing body of research is highlighting the importance of including embodied energy (see Sturgis \& Roberts 2010, Crawford \& Treloar 2005).

Location of housing is a major factor contributing to the greenhouse gas emissions associated with transport in cities (Kahn \& Glaeser 2010, Newman et al 2009, Newton 1997, Fuller \& Crawford 2011, Naess 1995). Extensive research has revealed the correlation between density and car dependency, demonstrating that as density increases, car dependency decreases (Newman \& Kenworthy 1999). The low-density design of Australian cities has meant they are overwhelmingly car dependent and therefore responsible for a significant proportion of transport related greenhouse gas emissions. Transport accounts for approximately $15 \%$ of Australia's national emissions with $87 \%$ of this attributed to road transport. Passenger vehicles are responsible for two thirds of road transport emissions (Commonwealth of Australia 2009).

Houses built in suburbs on the outer fringe of cities are also extremely land intensive, often replacing prime agricultural land or natural, biologically rich areas. Although this form of housing is gradually decreasing as cities put greater focus on infill development, it still remains the dominant type of new housing development in most of Australia's major cities (Commonwealth of Australia 2010b).

\subsection{Management of Resources}

Australia's high per capita footprints are not only a matter of excessive consumption, but also the way resources are produced and managed. Australian cities primarily use antiquated, large-scale, centralised infrastructure to manage resources. While traditionally great efficiencies were gained from employing large economies of scale, newer and more intelligent technologies are emerging at the local level that can arguably achieve greater resource efficiencies (Newman et al 2009). It is critical to recognize that most of the systems 
currently managing resources in Australia were developed using $19^{\text {th }}$ and $20^{\text {th }}$ century technologies which are now not only outdated and inefficient, but weren't originally designed to deal with the problems facing humanity in the $21^{\text {st }}$ century such as climate change and resource depletion. The question of whether these approaches are still the most effective way of dealing with resources today is something that needs to be discussed. The following provides a brief examination of the current management of energy, water and waste.

\section{Electricity}

The majority of Australia's electricity is supplied through centralised, coal-fired power generation using a system designed in 1940's (Garnaut 2008, Greenpeace 2005). This form of power generation is the primary cause of climate change worldwide and remains a significant challenge for global climate change mitigation (IPCC 2007). While burning coal produces significant emissions, it is the entire process that makes this form of power generation so inefficient and emission intensive. Around two thirds of the total energy generated during the process (i.e. thermal energy or steam) is wasted, released into the atmosphere. Further losses occur through the transmission and distribution (T\&D) networks, as the electricity is transported vast distances to when it is ultimately consumed. As a result, the efficiency of coal fired power generation is only around $33 \%$ (Greenpeace 2005, City of Sydney 2010).

\section{Water}

Water management in Australia is another example of a centralised, and arguably inefficient, process. Water is generally sourced in large volumes from a central location, treated to drinking standard (i.e. potable) and transported considerable distances to where it is consumed. The percentage of water actually used for potable purposes in urban areas amounts to less than 15\% (Chanan et al 2009) suggesting that much of this initial treatment process is unnecessary. This also highlights the vast potential for utilizing recycled water for nonpotable purposes.

While the majority of urban water is used for irrigation within cities, a significant proportion is also currently used for managing sewerage networks through a process designed over a millennia ago (van Lier \& Lettinga 1999, Chanan et al 2009). Valuable drinking water is used as a transportation medium, diluting and moving highly concentrated waste over large areas to where it is treated (van Lier \& Lettinga 1999). Stormwater is added to this system, increasing the overall amount of diluted wastewater to be treated. Such large volumes of diluted wastewater (argued to be more difficult to manage than more concentrated wastewater) create the need for large, centralised and therefore expensive, wastewater treatment plants and other associated infrastructure (Van Lier \& Lettinga 1999). After processing, the majority of the treated wastewater is discharged into waterways or the ocean. This is hardly an efficient process for a country known for its water scarcities.

The pumping and treatment of large quantities of water requires significant amounts of energy, contributing to greenhouse gas emissions (Kenway et al 2008). This amount of energy is likely to increase in the future if cities begin to source greater quantities of their water from energy intensive desalination plants (Productivity Commission 2011).

\section{Waste}

Australia's waste management is another emission intensive, centralised and outdated process. Around half of the materials and products that enter Australian cities exit as waste and are buried in landfill (Australian Government 2010a). This is one of the oldest forms of waste management. The process produces methane as materials decompose, adding considerably to GHG emission. There are also significant emissions associated with the collection and transportation of waste from cities to landfill sites. Finally, this process requires substantial tracts of land, which can remain contaminated and unusable for years after (Ikehata \& Liu 2011).

\subsection{Centralised versus Decentralised Systems}

These brief examples demonstrate two important characteristics of centralised systems for resource management. Firstly, they tend to function in isolation, ignoring important synergies and the potential efficiencies achievable when systems are combined. Secondly, they allow resources to flow through cities in a horizontal or linear fashion (Giradet 2004, Newman \& Jennings 2008). This is vastly different to how natural ecosystems function, which are based on circular flows and closed loop systems, where processes are inherently interconnected and resources and nutrients are continuously recycled.

Giradet (2004) argues for a greater system based approach for urban management that can help to create a more circular metabolism within our cities. Newman et al (2009) defines this metabolic city concept as the 'Eco-Efficient City', which demonstrates how various wastes can be turned into resources to radically 
improve the overall efficiency of systems. Many of these processes and systems are generally seen to be most effective at the smaller scale, usually at the district or community level (Newman and Jennings 2008, Newman et al 2009). These small-scale, integrated systems form part of a concept described here as decentralised green infrastructure. This is discussed below.

\section{DECENTRALISED GREEN INFRASTRUCTURE}

Green infrastructure is commonly referred to in urban planning literature as natural or biological infrastructure within cities such as trees, waterways, parks and 'green spaces' (Vandermuelen et al 2011). The authors, however, define green infrastructure as a broader term applied to alternative ways of supplying power and water and treating wastewater and solid waste that can help to achieve sustainability outcomes and reduce a city's carbon footprint. These are typically based on decentralised or distributed systems, which are small-scale systems for dealing with resources at the local level. These distributed systems are increasingly being shown to be more efficient and environmentally sustainable (Greenpeace 2005, Van Lier \& Lettinga 1999, Jones 2008, Jaccard et al 1997). Such systems and emerging technologies generally require sufficient densities of population to make them a viable infrastructure option. This is particularly the case in terms of decentralized energy infrastructure (Naess 1995). Some examples of this are provided below.

\subsection{Energy}

There are currently many different technologies supplying small-scale, distributed energy for cities. Solar photovoltaic, solar hot water and small-scale wind are some examples of renewable technologies servicing the individual household or building level, often referred to as micro-generation. Geothermal energy, co-, and tri-generation are examples of technologies that can provide alternative base load decentralised electricity at the precinct or district-scale and are becoming increasingly popular options for cities around the world determined to decarbonise (for example Borough of Woking, City of London and City of Sydney).

Co- and tri-generation are attractive options for numerous reasons. Firstly, the process runs on natural gas, which is significantly cleaner burning than coal. This means electricity can be generated within the city without local air pollution. This drastically reduces transmission and distribution losses as the electricity can be generated at, or close to, the point of consumption. Furthermore, natural gas can eventually be replaced with Synthetic gas (or syn-gas), made from renewable and/or waste products, providing a carbon free source of electricity. The main advantage of this technology, however, is that the thermal heat energy used to create the electricity is captured during the process and used to provide heating for neighbouring buildings. Adding an absorption chiller to the process can turn the heat energy into coolth, thereby also supplying air conditioning. This is known as "tri-generation" (Jones 2008, Greenpeace 2005, City of Sydney 2010)

Combining these three processes (i.e. electricity generation, heating and cooling) greatly increases the overall efficiency and, together with the reduction in transmissions losses means this process can achieve around $75 \%$ efficiency - far greater than large-scale coal-fired generation (Ge et al 2009, City of Sydney 2010, Greenpeace 2005).

Although co- and tri-generation can in theory work at any scale, it is generally only economically viable where there is sufficient building density and ideally mixed land use, to provide these additional services to (Jaccard et al 1997, Naess 1995). This means a shift in urban form from low-density, dispersed neighbourhoods to higher density activity centres, is required to facilitate the application of this transformative technology.

\subsection{Water}

It is argued that huge potential exists for significantly improving water management within cities by adopting a more decentralised approach that can promote greater integration of processes and helps to close loops (Newman \& Jennings 2008). Also referred to as a 'soft path' for water management (Chanan et al 2009), this approach promotes the integration of demand side (i.e. end-user efficiency) and supply side initiatives. It essentially involves sourcing, treating and managing water at the local level. This includes dramatically increasing rainwater harvesting and retention within cities, i.e. capturing stormwater runoff from rooftops and all impervious surfaces, treating and then re-using it rather than allowing it to flow into the sewer system. Hatt et al (2006) notes "The average annual volume of urban stormwater runoff in Australian cities is almost equal to the average annual urban water usage, of which at least $50 \%$ is for non-potable use" (p.103).

Water sensitive urban design using natural and biological systems, such as swales and buffers to collect and filter stormwater, can be implemented throughout cities and used to capture and treat water for re-use. Considering the majority of water in cities is used for non-drinking purposes (Chanan et al 2009), there are significant opportunities to use this recycled water. Treated black water and stormwater can be allowed to 
filter back through the earth to replenish aquifers, many of which are being depleted from an overdependency on ground water in particular locations. Domestic wastewater (i.e. sewerage), which has a high nutrient load, could be used (after treatment) as a natural fertiliser for applications such as agriculture (van Lier \& Lettiga 1999, Giradet 2004, Newman and Jennings 2008).

-Greater treatment and reuse of recycled water can provide cities and communities with a reliable source of water suitable for a variety of different end uses. It also reduces emissions and the need for desalination plants.

\subsection{Waste}

The very concept of waste is the problem lying at the heart of cities' inability to adopt more sustainable resource management practices. Waste implies that a material has come to the end of its productive life and no longer has any functional purpose (Tillman Lyle 2004). It is this anthropogenic invention of the concept of waste that does not exist in the natural world, which creates the unsustainable linear flow of resources through our cities. In order to overcome this and create more circular flows in cities, waste needs to be viewed as a resource.

The first step in any process should therefore be to reuse or recycle materials. Referred to as resource recovery, this will form an essential component in decarbonising cities. Organic domestic waste should be managed much more locally with nutrient rich organic matter being returned to farms after treatment to replace nutrients stripped out through intensive agricultural production methods, or alternatively, used for city gardens and urban food production. Materials that cannot be reused, recycled or broken down naturally can be treated by new technologies such as plasma arc gasification. This process reduces waste to $1 / 300$ of its original size as well as producing syn-gas, a renewable form of natural gas (Lombardi et al 2011). This gas can then be fed directly into the tri-generation system to create low carbon, renewable energy, thus providing a perfect example of a closed loop system (City of Sydney 2010).

Modern waste collection techniques include municipal vacuum waste, which sucks waste through an underground network of pipes to one or several collection points within a city. This can dramatically reduce the transport emissions associated with waste collection, improve the efficiency of recycling and add amenity by reducing the number of garbage trucks on the road (City of Sydney 2010).

\subsection{Benefits of Decentralised Approaches}

Managing resources more locally provides numerous benefits. Firstly, generating and managing resources closer to where they are being consumed can radically reduce transport emissions. Far greater integration between systems can also be achieved at the smaller scale, where for example, outputs from one process are used as inputs for another. This results in better resource efficiencies and reduces the overall amount of resources required and the emissions produced.

Decentralising resources can also reduce individuals' consumption by increasing their awareness of the resources they are consuming. It is argued that the centralised process for managing resources can leave many people disconnected, unaware or having little regard for the origin or final destination of the resources they consume (Giradet 2004). Decentralised processes and systems can bring people much closer to the life systems that support them. The increasing number of individuals, businesses and entire communities embracing opportunities for small-scale production and management of resources such as solar panels, rainwater tanks, community wind farms, biomass co-generation plants and community gardens are demonstrations of the willingness of people to move beyond the role of passive consumer.

While large-scale centralised processes are extremely vulnerable to disruptions (whether geo-political or natural disasters), decentralised options ensure reliable, localised supply and hence, greater security of resources. Numerous recent natural disasters have demonstrated how devastating the widespread failure of power, water and waste systems can be on entire cities. New Zealand provided an unfortunate example, where despite a relatively small area being severely impacted by the 2011 earthquake, whole neighbourhoods were left without power, sewerage disposal or clean water. Small scale, decentralised systems, although still connected to city wide networks, would effectively allow these local areas to continue to function or operate in an island type capacity.

Having a larger variety of sources and systems for managing resources adds diversity to the portfolio of supply options thereby reducing the risk associated with being dependent on a single source. Decentralised systems also carry less financial risk and are hence, more economically viable as they avoid the substantial investment and upfront costs associated with i.e. large power stations or new dams etc. This also reduces the risk of lock-in (i.e. rigid pathways for delivery of services over many years). 


\section{DENSITY AND GREEN INFRASTRUCTURE}

The new green infrastructure outlined in this paper is appealing to urban policy makers across the globe wanting to decarbonise their cities. There are several factors, however, that must be addressed as part of the change. Urban form, for example, cannot be separated from these emerging technologies. Precinct scale technologies and systems generally require adequate density to be most efficient and effective, as well as economically viable. In the case of Australia, this will mean increasing the density in most cities.

Increasing density has numerous other benefits, including enabling better public transport infrastructure such as light rail and trains as well as increasing the walkability of cities, all of which will drastically reduce transport emissions. Increasing density reduces the size of houses, significantly decreasing overall consumption of resources. While there are many other advantages of designing cities around denser centres, one overarching factor is that well-designed density can actually improve the liveability of cities by providing more amenities and better lifestyles.

\section{CONCLUSION}

The low-density design of Australian cities, together with the large-scale infrastructure for managing resources are key drivers to the environmental problems facing Australia and the principal reasons behind Australia's exceptionally large per capita carbon and ecological footprints. It is argued that these issues need to be addressed to ensure the long-term viability and sustainability of Australian cities. The authors propose that the solution will need to involve a transition to a new type of city model based on decentralised green infrastructure and distributed systems. While density and urban form will need to be addressed in order to make the above-mentioned technologies and systems viable options, density has numerous other sustainability benefits such as providing greater opportunities for better public transport infrastructure to reduce transport emissions. More compact urban form will also decrease per capita consumption of resources per dwelling such as heating and cooling as well as the embodied energy in materials.

Accepting that population growth in Australian cities, at least in the near to mid-term future is inevitable, the opportunity exists to use the expected growth to create the density required to enable the sustainability benefits outlined above. New policies must ensure, however, that growth is used to facilitate the transformative changes outlined in this paper, and not simply continue development along a business as usual pathway with ever expanding suburban development. If this can be achieved, then this new model for dense, green centres can be a key factor in reducing Australia's per capita carbon footprint.

\section{ACKNOWLEDGEMENTS}

The authors acknowledge the Australian Research Council for their financial support.

\section{REFERENCES}

Chanan, A., Kanasamy, S., Vigneswaran, S. \& Sharma, D (2009). A gradualist approach to address Australia's urban water challenge. Desalination. 249(3), 1012-1016.

City of Sydney (2010) Green Infrastructure for Sydney. Website. Available online: http://www.sydney2030.com.au/development-in-2030/city-wide-projects/powering-sydney-allan-jones Accessed on 10/05/2011.

Commonwealth of Australia (2008). Energy use in the Australian Residential Sector 1986-2020. Department of the Environment, Water, Heritage and the Arts, Canberra.

Commonwealth of Australia (2009). Australia's National Greenhouse Accounts: National Greenhouse Gas Inventory accounting for the Kyoto target. Department of Climate Change, Canberra.

Commonwealth of Australia (2010a). National Waste Policy: Fact Sheet. Department of the Environment, Water, Heritage and the Arts, Canberra.

Commonwealth of Australia (2010b). A Sustainable Population Strategy for Australia: Issues Paper and Appendices. Department of Sustainability, Environment, Water, Population and Communities, Canberra.

Crawford, R. \& Treloar, G. (2005). An assessment of the energy and water embodied in commercial building construction. Paper presented at the 4th Australian Life Cycle Assessment Conference, Sydney, 2005. Accessed online: http:/www.deakin.edu.au/dro/view/DU:30005640

Dodman, D. (2009). Blaming cities for climate change? An analysis of urban greenhouse gas emissions inventories. Environment and Urbanization. 21, 185-201.

Ikehata, K. \& Liu, Y. (2011) Land Disposal of Wastes. Encyclopedia of Environmental Health, 353-361.

Fuller, R. J. \& Crawford R. H. (2011). Impact of past and future residential housing development patterns on energy demand and related emissions. Journal of Housing and the Built Environment. 26, 165-183.

Garnaut, R. (2008). The Garnaut Climate Change Review- Final Report. Cambridge University Press, 
Melbourne.

Ge, Y.T., Tassou, S.A., Chaer, I. \& Suguartha, N. (2009) Performance evaluation of a tri-generation system with simulation and experiment. Applied Energy. 86, 2317-2336.

Giradet, H. (2004). Metabolism of Cities: from Creating Sustainable Cities. In Wheeler, S.M and T. Beatley (Eds.) The Sustainable Urban Development Reader, 125-132. Routledge New York.

Glaeser, E. L. \& Kahn M. E. (2010). The Greenness of Cities: Carbon Dioxide Emissions and Urban Development. Journal of Urban Economics. 67, 404 - 418

Global Footprint Network (2010) Ecological Footprint Atlas 2010. Available online under: http://www.footprintnetwork.org/images/uploads/Ecological_Footprint_Atlas_2010.pdf Accessed 26/08/2011.

Government of Western Australia (2010). Directions 2031 and Beyond: Metropolitan Planning beyond the horizon. Western Australian Planning Commission. Perth

Greenpeace (2005). Decentralising Power: An Energy Revolution for the $21^{\text {st }}$ Century. Available online under: http://www.greenpeace.org.uk/media/reports/decentralising-power-an-energy-revolution-for-the21st-century Accessed: 31/08/2011

Hatt, B,E., A. Deletic \& Fletcher T.D. (2005). Integrated treatment and recycling of stormwater: a review of Australian practice. Journal of Environmental Management. 79, 102-113.

IPCC (2007). Climate Change 2007: Mitigation of climate change, in B. Metz, O. Davidson, P. Bosch, R. Dave \& L. Meyer (eds) Contribution of Working Group III to the Fourth Assessment Report of the Intergovernmental Panel on Climate Change. Cambridge University Press, Cambridge.

Jaccard, M., L. Failing \& Berry. T. (1997). From equipment to infrastructure: community energy management and greenhouse gas emissions reduction. Energy Policy. 25(13), 1065-1074.

Jones, T. (2008) Distributed energy systems. In Newton, P.W. (ed.) Transitions: Pathways Towards Sustainable Urban Development in Australia, CSIRO Publ., Melbourne pp. 411 - 424. ,

Kenway, S.J., Priestly, A., Cook, S., Seo, S., Inman, M., Gregory, A. \& Hall, M. (2008) Energy Use in the Provision and Consumption of Urban Water in Australia and New Zealand. CSIRO: Water for a Healthy Country Flagship.

Lombardi, P., Carnevale, E. \& Corti, A. (2011) Analysis of energy recovery potential using innovative technologies of waste gasification. Waste Management. In press.

Naess, P. (1995) Central dimensions in a sustainable urban development. Sustainable Development. 3, 120 129.

Newman, P. \& Jennings, I. (2008). Cities as Sustainable Ecosystems: Principles and Practices. Island Press, Washington DC.

Newman, P. \& Kenworthy, J. (1999). Sustainability and Cities: Overcoming Automobile Dependence. Island Press, Washington DC.

Newman, P., Beatley, T., \& Boyer, H. (2009). Resilient Cities: Responding to Peak Oil and Climate Change. Island Press, Washington DC.

Newton, P.W. (ed) (1997). Re-Shaping Cities for a More Sustainable Future - Exploring the Link Between Urban Form, Air Quality, Energy \& Greenhouse Gas Emissions, Research Monograph 6, AHURI, Melbourne.

Pitt, A. (2010) Energy in High Density Cities. In Ng, E (Ed) Designing High Density Cities: For social \& Environmental Sustainability. Earthscan. UK. pp. $263-271$

Productivity Commission (2010). Population and Migration: Understanding the Numbers,

Commission Research Paper. Available online under: http://www.pc.gov.au/research/commissionresearch/population-migration Accessed 26/08/2011.

Productivity Commission (2011). Australia's Urban Water Sector, Productivity Commission Draft Report April 2011. Available online under: http:/www.pc.gov.au/_data/assets/pdf file/0006/107745/urbanwater-draft.pdf Accessed 6/10/11.

Sturgis, S. \& Roberts, G. (2010). Redefining Zero: Carbon Profiling as a Solution to Whole Life Carbon Emission Measurement in Buildings. Research Report May 2010. RICS, London.

Tillman Lyle, J. (2004) Waste as a Resource. In Wheeler, S.M and T. Beatley (Eds.) The Sustainable Urban Development Reader, 133-140. Routledge New York.

Van Lier, J.B. \& Lettiga, G. (1999). Appropriate technologies for effective management of industrial and domestic waste waters: the decentralised approach. Water, Science and Technology 40(7), 171-183

Vandermuelen, V., Verspecht, A., Vermeire, B., Van Huylenbroeck, G. and Gellynck, X. (2011). The use of economic valuation to create public support for green infrastructure investments in urban areas.

Landscape and Urban Planning. 103, 198-206 